\title{
Reliability Augmentation through Technological Applications in Indian Aircraft Maintenance Training sector
}

\author{
C.S. Karunakaran a , Joned Harun David ${ }^{\text {b }}$, George Kishore. S c , M. Mohamed Umar Ali d, J. Ashok Babu \\ e, J. Khaja Sheriff ${ }^{\mathrm{f}}$

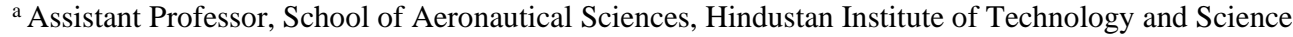 \\ b, c, d Student, School of Aeronautical Sciences, Hindustan Institute of Technology and Science \\ ${ }^{e}$ Professor, School of Aeronautical Sciences, Hindustan Institute of Technology and Science \\ ${ }^{\mathrm{f}}$ Professor and Head, Department of Management, University of Madras
}

Article History: Received: 10 January 2021; Revised: 12 February 2021; Accepted: 27 March 2021; Published online: 10 May 2021

\begin{abstract}
The paper focuses on the technological needs in Indian aircraft maintenance training sector towards reducing the human errors and to enhance the maintenance reliability. An overview of Indian MRO s' skill requirements and the immediate necessity to improve the standards in maintenance human factors and technology based training is elaborated. The existing level of Indian AMT training in comparison to international standards are discussed to spot the areas with scope of improvement and the weak link in existing process. Need of maintenance training with intense knowledge and practical exposure can downturn maintenance errors and aid in cutting cost of the maintenance expenditure by increasing reliability were discussed. Impact of Computerised Maintenance Management System (CMMS), in augmenting current maintenance performance and its importance in terms of efficient operation and Labour maintenance were reviewed. Technology identification to address the need for improvement in traditional training, using the applications of Virtual Reality (VR) and Augmented Reality (AR) in maintenance training would equip the Aircraft Maintenance Trainees (AMT's) with complete knowledge and practice were analysed. This view point can be a thought provoking research to evaluate a right road map for improving the current Indian aircraft maintenance training sector to global standards resulting in optimising the state of India's MRO self-reliance ability.
\end{abstract}

Keywords: MRO Training, Aircraft Maintenance, Human Factors, Training, Aircraft Maintenance Training, Computerised Maintenance Management System, Advancement in Aircraft Maintenance, Indian MRO

\section{Introduction}

The aircraft is made functional and reliable to the respective airlines and its passengers. Reliability design concerns how to prevent or minimize and maintain failures and faults of a system. This can be ensured by performing tests, models and analysis and change the designs if problems are detected [5]. Aircraft maintenance is a critical and crucial factor where success is most required and failure to do so may lead to accidents. In addition to accidents, these errors can also be reasons for flight delays and cancellations where the financial area takes a huge hit [19]. The mandatory requirement in aviation industry is safety and security as they are crucial [16]. The outmoded rules of maintenance system and its structure make its application infeasible. This needs a research on ideal representation of economically structured aircraft maintenance industry and the use of viable mathematical representation for the process [13].

Surveys indicate that aviation maintenance documents are stored using an outdated paper-based approach and this makes the process of maintenance difficult for stakeholders involved. To maintain accuracy and system's specification and its documentation, the authors propose a supportive systematic approach for the design process of complex systems [6]. A good understanding on human factors is necessary as they contribute to a majority of aviation accidents and incidents. Human error more than mechanical error underlines most aviation accidents in recent times. When an aviation maintenance technician makes a mistake, the person is oftentimes present but is not visible, which can affect the safety and security of aviation and their operations for a longer period of time. Due to advanced aircraft design techniques, there have been considerably greater improvements in design and reliability of components however the maintenance schedule of modern aircrafts still requires repeated maintenance, overhaul and inspection for longer and effective functioning of the aircrafts which require human interventions which remain vulnerable to failure and accidents. This paper aims to improve and provide Aircraft Maintenance Technicians and Trainees a viable and reliable source of Augmentation by inducting the applications of AR and VR in Aircraft Maintenance to reduce Human Errors and hence improve the efficiency of Aircraft Maintenance [19].

\section{HF Needs IN Aircraft Maintenance Training}

Aircraft maintenances are critical and crucial success factors and even a slight incorrect maintenance action can lead to accidents in the aviation sector. In aviation, Maintenance related accidents have one usual factor being Judgemental Errors. The two automatic thought types are heuristic bias and skilled intuition [15]. Errors caused by humans should be minimized in order to increase air transportation safety, with respect to the cause of aviation incidents and accidents. The industry should take into consideration human factors which put people 
having crucial roles under stressful situations. This significantly minimises the errors [7]. Detection, diagnosis and prognosis are three important phases where once a behaviour that deviates is detected, cause of action is diagnosed and future performance can be predicted which can be corrected through preventive [15]. Even after preventing eerrors pilots are the final weapon to avoid air crashes. Even though there is a drastic quality improvement in equipment, manufacturing and design, still defect causes $20 \%$ accidents. Hence there needs to be a great requirement of responsibility in aircraft maintenance management. Maintenance is the process which ensures the component or system of an aircraft to work as it was designed to work. This is necessary as all components have their own service life, once the service life is completed and it does or does not work at that point, the components needs to either way be replaced. Thus proper care and well supported treatment will make an aircraft function efficiently and assure the safety and reliability of the aircraft maintaining the flight to be in good condition [16].

Human factor is one of the major problems in maintenance industries. Human Factor study should be applied in aviation towards understanding the problem in HF perspective and to reduce the percentage of errors [4]. There should not be any pathway that allows any deviant decision making to arise and prosper over logically formed command requirements in a highly regulated and consequence prone industry such as aviation. Operatives, who are well trained along with efficient supervision and engaged management, should take proper informed decisions siding to compliant process and outcomes. Aircraft maintenance manuals are descriptive, direct and detailed procedures and are comprehensively linked to technical data given by the manufacturers of the original equipment for the most part and are subjected to periodic updates and design engineering developments. Failure to follow these procedures and manuals within the aviation domain and deviating from them are identified as a substantial factor in aviation accidents and tragedies. These deviations can't be considered as random events. Innovation can be positive but not at the expense of deviation in decision making and following procedures which may in most cases lead to accidents and hence are supposed to have boundaries. There is a boundary which separates positive deviant decision making and violation and certain factors such as understanding attitudes towards compliance, defining the impact of individual behaviours, establishing organisational norms, evaluating casual factors in aviation events can help bring the boundaries into focus by putting actions which give deviance decision capture options[2].

As new failure modes are discovered and as technology advances, the documents such as troubleshooting manuals are updated. The behavior of the actual maintenance system however does not directly link with the documentation. This result in the impact of a failure model may not be well understood or well modeled from the documentation. The further traceability of maintenance process to asset management practices and documentation reduces overall. It also says that Model-based systems engineering (MBSE) is a practice which allows engineers to create models automatically generating all the artifacts that's needed for a given system [6]. Aircraft operators and maintenance organisations expect them to maintain the publications and processes authorised by the maintenance personnel strictly. However situations and instances where there is deviation in procedure of maintenance are substantial factors in aviation accidents. Deviation from approved procedure by aviation maintenance personnel impacted by intuitive influence by safety culture and climate within the organisation which are evident and demonstrable. The maintenance personnel continuously make simple and complex decisions through their entire shifts which many a times involve such decisions that involve aircraft operating systems and critical safety items and thus such decisions impact aircraft airworthiness and safety of the others such as the crew, passengers and other maintainers[2].

\section{Level of Maintenance Training In India}

Statistics show that there has been significant growth in just the last decade and that in 2019 alone there were around 39 million flights maintaining flight schedules and ensuring high safety reliability worldwide. Airlines are supposed to maintain the quality of maintenance that is provided to the aircraft and needs to ensure that the availability of fleet remains high in order to do so. Maintenance demand, constraints and quality are several factors for which fleet availability is a function. The operation of an aircraft solely depends on aircraft maintenance as it plays a significant role [6]. Studies show that $26 \%$ of accidents were caused by maintenance failures and hence caused this accident chain. The human factors/errors have grown increasingly over mechanical failures and this realized by the aviation industry underlines most aviation accidents and incidents and where $80 \%$ are caused by human errors which do not just include maintenance errors but also errors caused by pilots and air traffic controllers[19]. 158 people were killed in 2010 when an Air India aircraft which departed from Dubai overshot the runway and slip downhill in Mangalore. Likewise, another Air India aircraft namely IX1344 from Dubai overshot the runway killing 18 people out of 190 onboard which included two pilots in Calicut. The credibility as a responsible member of the ICAO started facing challenges. Several investigation agencies along with the Court of Inquiry and Committee Inquiry was established by the DGCA to act in accordance with the Standards And Recommended Practices (SARPs) of the ICAO before the Aircraft Amendment Bill 2020. The impact of such downgrade such as lack of training opportunities for trainers, lack of expertise, lack of authority with the inspectors, shortage of flight operation inspectors and immature handling of accidents by the bodies such as the FAA, ICAO and EASA is bad for the country and also the country's economic impact [21]. 
It is expected that by 2022, the Indian aviation market will be the third largest market and by 2040 India would handle 1,124 million passengers. USD723 billion has been spent on MRO sector and 90\% of that is spent outside of India [4]. Skill shortage is the main bottleneck for the Indian Civil Aviation growth associated with local labor demand in the maintenance sector. Due to this, there is a need for the Aircraft maintenance organizations and companies in India to hire technicians from abroad [4]. Lack of competitive and high standard in-house MRO plays a vital role in poor student training problems. After several years of job preparation, airlines were usually pursued by engineers who are licensed after long on-job-training mode of experience [4]. This will not help to fulfill the requirement and will hinder the growth of maintenance industry [4]. One major drawbacks of the Indian MRO sector is its weak training facilities. The standard of the institutes and technicians approved by DGCA for MRO work is low, which is required every two years for retraining [4]. India is expected to gain three times the average earnings of MRO companies in the next ten years. To handle the industry demand India's large private aviation institutions must enhance their training and infrastructure facilities. Indian economy is about USD 2.72 trillion in which $0.03 \%$ gain can be achieved by retaining $100 \%$ business of its MRO sector [4]. India could lead in MRO business and training if this goal is achieved [4].

As by conducting simulator and maintenance system operation aviation organization can maximize safety. Even a leading airline can experience accidents and incidents and hence the pilot's performance and possible approach of airline towards the maintenance should be optimized. Hence airline safety can by ensured by maintenance management and pilot simulator training [16]. Airspace system permanent changes relies on strategic modeling whereas flow management and tactical modeling relies on air traffic control [12]. The maintenance system should have an effective simulator training module to prepare pilot both mentally and physically to face critical accident condition towards reducing the risk through situation handling skills. This will improve the aviation safety [16].

\section{Role of CMMS in Maintenance Training}

Human errors in aircraft maintenance can be solved by combining risk management safety reporting system and HF analysis. Maintenance, fuel and skilled labor are equally important as like safety and also should be properly balanced. Commercial airliners spend a major amount of expenditure on aircraft maintenance as it comprises safety as core focus. Maintenance based human errors stands as a great threat for safety of man and material and airline economy. Adding to man and material loss even delayed arrival end up frustrating passengers and overnight hotel and stay costs, in certain situations. Maintenance malpractices lead to accidents, increased expenditures and leads to causalities and catastrophic damages. More than economy loss and mishaps the work burden of maintenance technicians who replace the injured personal and customer dissatisfaction is always unnoticed. The airliners that have been through such challenges need to gain their trust back from their various stakeholders. Human factors that are incorporated through a safety reporting system ensures technicians to timely report and identify hazards. By implementing HF education maintenance technicians avoid accidents thus resulting in profitability of the commercial airlines [14].

By using computer based systems, aircraft maintenance tasks can be performed more effectively without any mishaps and errors. Augmented Reality (AR) is an effective technological support which aids in advanced interactive visual systems and aids in implementing effective and better choices of recording the maintenance data in digital format [7]. The CMMS is an enabler for maintenance efficiency, not a driver. A CMMS is a transactional instrument for management reporting and accounting in its most basic form. It is a strategic and operational monitoring tool with management involvement [17]. Planning and scheduling is a key feature which receives little attention, which is the reason why maintenance performance is often less than excellent [17]. There is a need for a change in the work paradigm, and a CMMS is the perfect tool to fix this problem, and should be the priority during implementation. Job management, asset registry, Preventive Maintenance (PM), labor and inventory are the most important modules in a CMMS. It is important to populate these modules with the required data. To kick-start an implementation effort, guidelines and examples for creating data sets for each main module are presented. There will be no discussion of technical set-up and configuration specifics, since these are brand-specific [17].CMMS operates and produces reports as a data repository. It becomes a powerful method for handling maintenance functions: searching for equipment details and history, compiling the

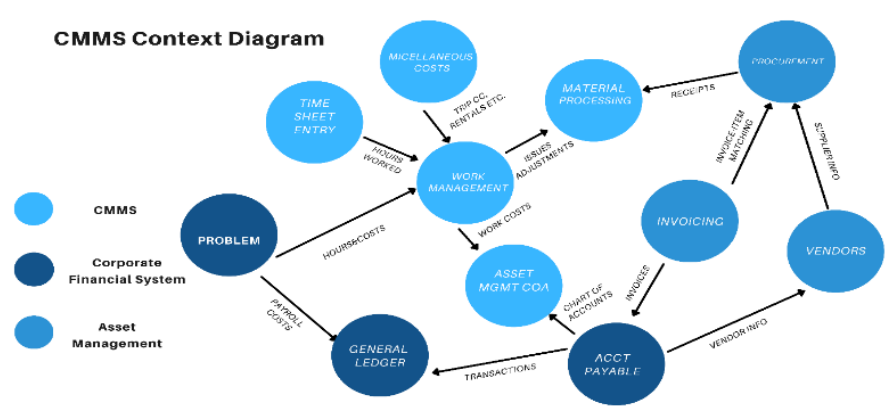


necessary materials and resources, and waiting for output to release the equipment, integrating it with processes and individuals to join, process and act on information [17]. The context diagram for CMMS is given in figure 1.

FIG 1 : CMMS Context Diagram

CMMS product will have distinct features and different terminology, but the basic functionalities are similar to all:

EQUIPMENT MANAGEMENT includes details of equipment, such as dimensions, locations and maintenance history.[17] WORK MANAGEMENT covers scheduled and unplanned work management, PM's, job plans/tasks, resource planning and transaction posting. PARTS INVENTORY MANAGEMENT, including reservation, issuance, field returns, where-used, and reorder data PROCUREMENT MANAGEMENT, including requisitioning, purchasing orders, information about vendors, receiving stores and warranty claims LABOR/PERSONNEL MANAGEMENT, which involves classification of talents, pay grades, preparation and

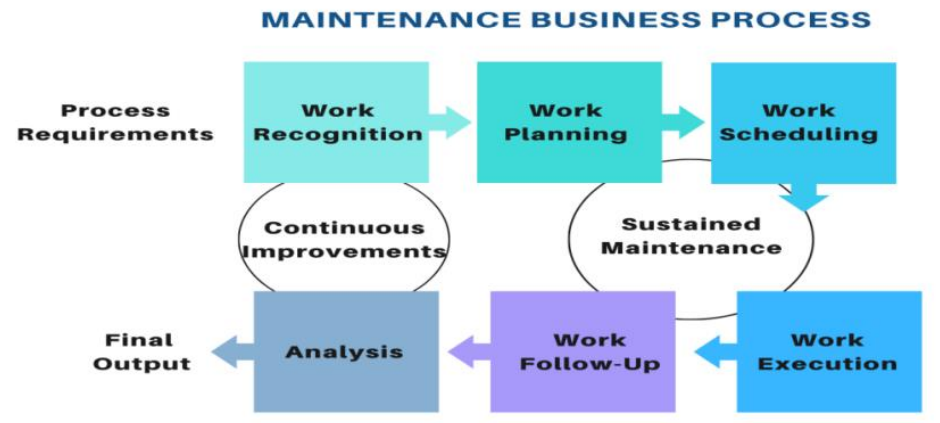

holiday schedules. REPORTING, the CMMS's key output and its most significant feature. Canned (packaged) reports are usually issued, but personalized reports may be accommodated [17].

\section{FIG 2 : Maintenance Business Process}

It must be applied when a CMMS is purchased in such a way that it becomes an integral part of the maintenance organization. If not already known, maintenance strategies, such as those resulting from Reliability Focused Maintenance (RCM), Reliability Dependent Inspections (RBI), should be specified so that criticalities for equipment can be allocated [17]. The CMMS is not intuitive, and preparation must be undertaken to use the CMMS. Initially, vendor trainers must be actively involved to explain how it is intended to be used [17]. Programmers are not considered trainers for CMMS. For the CMMS implementation, a dedicated core implementation team is created, and after going live, the team assumes trainer roles [17]. Training must be performed regularly and as refresher training to fit new users. The process for maintenance business is given in figure 2 .

\section{Necessity of VR and AR Based Maintenance Training}

Today's Aircraft maintenance training - although effective - relies on traditional teaching, video guides and written training handouts with supporting component maintenance manuals. This is where Augmented Reality(AR) and Virtual Reality(VR) provides effective solutions. In AR, 3D design is superimposed over the real component view when a technician overlooks the component to be maintained. This guides the technician to perform the required maintenance task in right sequence without missing out any task. VR is a computer simulation where the user interacts and immerses in the artificial 3D world.

Aircraft malfunction just before takeoff may lead to ground the aircraft which might cost an airline USD150,000 per hour. The market of AR and VR aviation application in 2019 was USD 78 million and it is expected to grow up to USD1.37 billion by 2025. MRO Network's reports that by 2036 current civil aviation passenger traffic might be doubled. This market growth expectation has created sudden demand, as more engineers and mechanics should be trained by the aviation industry to manage the requirements in short period of time. USD4.5 million costing high end simulator training can be replaced by USD1000 costing VR kit [9].

There are different ways in which AR can be used to train Aircraft Maintenance Trainees (AMT's). In a real world environment, various task based job trainings can be effectively facilitated to trainee technicians through AR [20]. AR system effectively processes human information with task based job approach to minimize the aircraft maintenance training expenditure for technicians [20]. AMT can perform a high reliable task in a shorter period with a required job knowledge if AR system support is provided. A basic VR kit component detail is explained in table 1 .

Table 1 : VR Kit component details

\begin{tabular}{|l|l|l}
\hline $\begin{array}{l}\text { Equipment Required } \\
\text { (Hardware \& Software) }\end{array}$ & Specifications & Applications \\
\hline
\end{tabular}




\begin{tabular}{|l|l|l|}
\hline 360 degree Camera & GoPro 360 action & To shoot the raw 360 videos \\
\hline Unity 3D & Version 2018.4 & $\begin{array}{l}\text { Rendering the videos and rapid } \\
\text { iterative development }\end{array}$ \\
\hline Google SDK for Unity & GVR SDK for Unity v1.200.1 & $\begin{array}{l}\text { Setting up android studios for Google } \\
\text { VR Development }\end{array}$ \\
\hline Cardboard Headset & Google Cardboard & To provide VR for the viewer \\
\hline Android Mobile Phone & Android 4.4 'Kitkat' or higher & To view the VR content \\
\hline
\end{tabular}

AR systems can effectively improve the quality of inspection in reassembly of components and construction of structures [20]. The employees were directed to the parts by this AR method, and verbal orders indicate which part should be collected for use. In order to allow the machine to check that the correct component was chosen a barcode scan helps to superimpose the component graphic over the component view and aids in installation process through sequential verbal and visual instructions [20]. AR helps in following maintenance procedures through superimposing the inspection process while performing a maintenance task [20]. This reduces the troubleshooting time and maintenance manual reference time and improves the repair reliability [20]. Another important function of an AR system is image recognition. Visual aircraft recognition (VACR) aids in finding friend or foe based approach in military applications with exterior visuals [22].

Table 2: AR Kit Specifications

\begin{tabular}{|l|l|l|}
\hline $\begin{array}{l}\text { Equipment Required } \\
\text { (Hardware \& Software) }\end{array}$ & Specifications & Applications \\
\hline Vuforia & Version 9.5 & $\begin{array}{l}\text { Mobile devices uses as AR software } \\
\text { development kit (SDK). } \\
\text { AR applications }\end{array}$ \\
\hline Unity 3D & Version 2018.4 & Applying AR to real world tasks. \\
\hline Android Mobile Phone & $\begin{array}{l}\text { Android 4.4 'Kitkat' or } \\
\text { higher }\end{array}$ & To feed the real world content \\
\hline
\end{tabular}

Similarly, VR can be used during aircraft ground inspections, visual and walk around inspections [3]. The VR modules are created according to the procedures. Both these modules run in either 2D or VR modes on iOS or Android phones and tablets [3]. Trainees will practice parking a jet at a terminal in a practical way and actually take the required measures to get an aircraft ready to take off. The trainees will acquire hands-on experience with a smartphone and a VR kit in spite of their locations where they are. The progress of trainees and required practices can be managed by LMS application [3]. It involves both advances in hardware and software, plus convergence of systems. A physical model combined VR can measure the human force application for performing the functions [1]. Image creation, object detection and collision control are interfaced with PC LAN to collect task based data [1]. Walk-around equivalent to what you would encounter on the runway is included in the VR training [3]. The trainee would enter the plane and use the same checklist to do the same inspection they will do in the real world. Trainees can perform sequential tasks with possibilities to fail or succeed in the assigned tasks with an advantage of zero damage cost while the software will access and inform trainees about the amount of real-time damage done by trainees with a note of required corrective actions to be taken [3]. The applications of AR can be also tested in learning techniques. Knowledge Objects for Augmented Reality (ARKO) is an AR application, which ensures the environment of AR utilization modes. Animated virtual design combines with real-time image to create AR [10]. Using a web camera as a tangible device, the user may communicate with a virtual entity [10]. The AR kit specifications are given in table 2.

The documentations are animated through digitalized data this assures an innovative technological opportunity interface in training domain [7]. Airbus' RHEA (Realistic Human Experiment Analysis) provides a full aircraft training through digital aircraft model in AR [18]. The headsets accurately displays the body movements and the sensors installed on the user's body (arms and legs) are tracked by the cameras [18]. In the maintenance of aircraft, regular inspection is a significant element. It consists of an external inspection and an internal inspection. Each inspection is structured into a number of tasks corresponding to various controls and aircraft systems and subsystems [7]. For example, we could increase the individual steps in the oil check subtask where human error is possible by animated instructions and digital data graphic to guide technicians and operators properly [7]. Mixed Reality (MR), is a larger technology which combines both AR and VR can also be effective in maintenance practices. In aero engine maintenance, crack detection is of significant importance. The automated crack detection system uses robot directed white light interferometer (WLI) for combustion chamber cracks [8]. The results are evaluated through image processing manually. A large number of manual procedures are conducted during the tests. With the help of MR, the so-called ground test instructions describe the test process (GTI)[8].

\section{Conclusion}


The work carried out in the discussion details the lack of conventional aircraft maintenance training and its alternate solution through AR and VR applications with a 1.3 billion growth of VR applications in next 4 years. The study clearly details the cause of human errors in maintenance accidents and poor Indian aircraft maintenance training sector. The Indian maintenance sector has $2 \%$ of skilled maintenance manpower to handle the workload if its $100 \%$ MRO business is retained. With the current Indian maintenance training institution facilities which is lacking to provide hands on experience and human factors training to its AMT trainees, the ambitious aim to retain MRO business within India will face a huge bottle neck in terms of available skilled technicians. This will again add burden to operators to train the fresher in maintenance skills and human factors. The current trend in maintenance accidents also will continue without reduction unless the flaws in maintenance training are addressed by the Indian training sector. Through this work it is clear that AR and VR training framework will effectively contribute a positive impact in improving the needs of Indian aircraft maintenance training industry. An effective current simulator training setup costing USD4.5 million can be replaced by an AR and VR kit costing USD1000 which brings 4500 times of cost reduction in equipment cost itself. Maintenance training in AR and VR application will be able to simulate any aircraft and its systems to trainees; this feature gives more advantage to the training institutions for providing better training. Investment of USD40,000 by 40 India's top aircraft maintenance institutions can bring a promising impact to provide $70 \%$ required maintenance manpower to retain USD723 billion MRO market within India if supported with required infrastructure.

\section{References:}

[1] A. Amundarain, D. Borro, A. García-Alonso, J. J. Gil, L. Matey, J. Savall, "Virtual Reality for aircraft engines maintainability", Article published by EDP Sciences Mechanics and Industry, available at : [https://www.mechanics-industry.org/articles/meca/abs/2004/02/mivc1/mivc1.html]

[2] Anthony Ronald Bannister-Tyrrell,"Uncertain outcomes: Traversing the breach between innovation and violation in aviation maintenance”, PhD Thesis University of Newcastle Australia, December 2020, available at : [https://www.researchgate.net/publication/347504669_Uncertain_outcomes-

Traversing_the_breach_between_innovation_and_violation_in_aviation_maintenance]

[3] "Augmented and Virtual Reality Aerospace and Transportation", Article by EON Reality, available at : [https://eonreality.com/use-cases/augmented-virtual-reality-aerospace-transportation/]

[4] C.S. Karunakaran, J. Ashok Babu and J. Khaja Sheriff,"Indian MRO industry: Business retention and development opportunities pre COVID-19”, published in Elsevier Materials Today Proceedings, $9^{\text {th }}$ August 2020, [https://www.sciencedirect.com/science/article/pii/S2214785320355619?via\%3Dihub]

[5]Enrico ZIO, Mengfei FAN, Zhiguo ZENG, Rui KANG, "Application of reliability technologies in civil aviation: Lessons learnt and perspectives", published in Chinese journal of Aeronautics, January 2019, available at : [https://www.sciencedirect.com/science/article/pii/S1000936118301948?via\%3Dihub]

[6] Fatine Elakramine, Niamat Ullah Ibne Hossain, Raed Jaradat, Ph.D., Chad Kerr, Morteza Nagahi, "The Application of System Modeling Language (SYSML) in an Aviation Structure and Maintenance System", Conference paper, Mississippi State University, uploaded in Research Gate on 03 November 2020, available at : [https://www.researchgate.net/publication/345214511_THE_APPLICATION_OF_SYSTEM_MODELLING_L ANGUAGE_SYSML_IN_AN_AVIATION_STRUCTURE_AND_MAINTENANAECE_SYSTEM]

[7] Francesca De Crescenzio, Massimiliano Fantini, Franco Persiani, Luigi Di Stefano, Pietro Azzari, and Samuele Salti, “Augmented Reality for Aircraft Maintenance Training and Operations Support”,Source: IEEE Xplore, published in IEEE Computer Graphics and Applications, March 2011, available at : [https://ieeexplore.ieee.org/document/5675633]

[8] Henrik Eschena, Tobias Köttera, Rebecca Rodecka, Martin Harnischa and Thorsten Schüppstuhl, "Augmented and Virtual Reality for Inspection and Maintenance Processes in the Aviation Industry" published in Elsevier Procedia Manufacturing, Conference Paper Hamburg University of Technology Germany Nov 2017, available at : [https://d-nb.info/1171900279/34]

[9] "Improving Aviation Safety and Reducing Costs with Immersive Technology", Article from Circuit Stream published on February 3, 2020, available at : [https://circuitstream.com/blog/aviation-safety-and-cost/]

[10] Johannes Christian, Horst Krieger, Andreas Holzinger, Reinhold Behringer, "Virtual and Mixed Reality Interfaces for e-Training: Examples of Applications in Light Aircraft Maintenance" , Conference paper published by Springer Link, 2007, as a part of lecture notes in computer science book, available at : [https://link.springer.com/chapter/10.1007\%2F978-3-540-73283-9_58]

[11] Leon Pete Kelley, "General and Specific Realities of Aircraft Maintenance"; General Paper published on July 2016, Research Gate, available at : [https://www.researchgate.net/publication/304627916_General_and_Specific_Realities_of_Aircraft_Maintenanc e]

[12] Lisa A. Schaefer Leonard A. Wojcik Thomas P. Berry Craig R. Wanke, "Decision Support For Advanced Aviation Concepts", Conference paper Center for Advanced Aviation System Development The MITRE Corporation McLean, U.S.A.; January 2002, Source: DBLP, available at : [https://www.researchgate.net/publication/221529360_Advanced_aviation_concepts_via_simulation_decision_s upport_for_advanced_aviation_concepts] 
[13] M. A. Kovalev, I. V. Poddubniy , "Problems Of Modern Aircraft Maintenance"; Article from Samara National Research University, July 2019, available at [https://journals.ssau.ru/index.php/vestnik/article/view/6761]

[14] Miller, M. D., \& Mrusek, B.,"REPAIRER Reporting System User Analysis for SMS Compliance in Aviation Maintenance", Conference Paper Advances in Safety Management and Human Performance, 1204, published in Springer Link, Embry-Riddle Aeronautical Engineering Scholarly Commons and first online on 1 July 2020,available at : [https://doi.org/ 10.1007/978-3-030-50946-0_8]

[15] Prasanna Illankoon, Phillip Tretten, “Judgemental errors in aviation maintenance" published in Springer Link, Cognition Technology and Work, on 28 October 2019, available at : [https://doi.org/10.1007/s10111-01900609-9]

[16] S. D. Rahmawati, S. J. R. Maulida, S. Rafi, Devi Ratnasari, "Effect Of Maintenance System And Simulator Pilots On Aviation Safety In Airlines"; ICSTEEM 2019 and 3rd Grostlog 2019, Journal of Physics: Conference Series, Vol 1573 (2020), IOP Publishing (IOP Science), available at : [https://iopscience.iop.org/article/10.1088/1742-6596/1573/1/012027]

[17] Senduk, Rachmar, "Principles of CMMS Implementation", November 2018, Paper for International Maintainability, Availability, Process Safety, Reliability Exhibition \& Conference, available at : [https://www.researchgate.net/publication/328968694_PRINCIPLES_OF_CMMS_IMPLEMENTATION]

[18] "Stepping into the virtual world to enhance aircraft maintenance", Airbus article, 8 February 2019, available at : [https://www.airbus.com/newsroom/stories/stepping-into-the-virtual-world-to-enhance-aircraft-maintenance.html]

[19]Tai Wei Jiang, Nora Palmer, Jingfei Peng, “An Inductive Study of Aviation Maintenance Human Errors and Risk Controls", Research paper Purdue University USA, published in Research Gate on December 2020, available at

[https://www.researchgate.net/publication/347932665_An_Inductive_Study_of_Aviation_Maintenance_Human_ Errors_and_Risk_Controls]

[20] Tom Haritos and Nickolas D. Macchiarella,"A mobile application of augmented reality for aerospace maintenance training", published by IEEE Explore on 27 December 2005, available at : [https://ieeexplore.ieee.org/document/1563376]

[21] Wing Commander Rakesh Yadav, "Problems with Civil Aviation in India and suggestions to improve the situaton", Research Gate April 2020, uploaded on 06 November 2020, available at : [https://www.researchgate.net/publication/345360276_Problems_with_Civil_Aviation_in_India]

[22] Worawat Choensawat and Kingkarn Sookhanaphibarn "AArcraft Recognition Training Simulator using Virtual Reality”, published by IEEE Explore on 27 February 2020, available at : [https://ieeexplore.ieee.org/document/9015524] 